\title{
A Brief Analysis of SPOC's Advanced Mathematics Curriculum Exploration and Practice
}

\author{
Hongping Cheng \\ Xi'an Eurasia University, Xi'an, Shaanxi, 710065, China
}

Keywords: Higher mathematics, Mathematics education, SPOC, Educational model innovation.

\begin{abstract}
The SPOC mode is a brand-new teaching form, which has a very positive effect on improving the quality of teaching. In the teaching practice of advanced mathematics courses, the SPOC mode also played an effective role in improving the quality of teaching. However, there are still some problems. Therefore, exploring the effectiveness of the SPOC mode in the teaching of advanced mathematics and solving the existing problems is the key to promoting the application of the SPOC mode.
\end{abstract}

\section{Introduction}

With the continuous development of science and technology, the form of classroom teaching is also constantly being transformed and upgraded. Before the paper-mediated communication of knowledge was to some extent replaced by electronic resources. Under this situation, the SPOC teaching method came into being. This is a brand-new teaching form developed on the basis of Internet technology. Under the background of curriculum reform, the SPOC model has not only improved the quality of teaching, but also helped to get rid of tradition. The shackles of the teaching style and the cultivation of students' learning abilities also have a very significant role [1]. Therefore, it is of great theoretical and practical significance to deeply study the SPOC model of higher mathematics curriculum.

\section{Basic education concept of SPOC mode}

The concept of SPOC (Small Private Online Course) was first proposed and used by Professor Armand Fox of the University of California, Berkeley. Small and Private are relative to Massive and Open in SPOC. Small refers to students from tens to hundreds, and Private refers to restrictive entry conditions for students. Applicants who meet the requirements can be included. SPOC course [2]. To a certain extent, the SPOC model is a subversion and innovation of the traditional teaching classroom, because in the previous higher mathematics curriculum teaching practice, the teacher first explained the advanced mathematics knowledge to the students, and then the students went back to study themselves. The process of learning was Under the guidance of the teacher, the so-called "teaching before school" education model. The SPOC model changed the teaching sequence and teaching structure of the past, allowing students to self-learn the knowledge spread through teachers through the Internet. When problems occur in the learning process, they are then focused on discussion and resolution in the classroom. This is the so-called "learning after school". mode. Compared with the previous teaching methods, the SPOC mode teaching improves the pertinence and effectiveness of higher mathematics teaching, enables valuable classroom time to be used efficiently, and enables each student to study according to his own learning style and rhythm. The knowledge of mathematics curriculum has realized the differentiation of teaching, and has made it possible to advocate the concept of teaching students in accordance with their aptitude. It is also in line with the overall trend of current education development and effectively improves the quality of classroom teaching. 


\section{Application Status of Higher Mathematics Course SPOC Mode}

Since the SPOC teaching mode came into being, there has been continuous research on relevant aspects. From the viewpoint of the number of papers, the number of papers on the SPOC model has shown a sharp upward trend in recent years. It can be seen that the SPOC model is completely new. The higher mathematics curriculum teaching style can play a positive role in improving teaching quality if it can be applied in the teaching process, and the SPOC model also meets the overall requirements for the development of the education situation [3]. In the teaching practice of higher mathematics courses, there is relatively little research on the SPOC model. Therefore, applying the SPOC model in the teaching process is still new and lacks certain experience as guidance. This will inevitably lead to certain problems. Although some teachers apply the SPOC model in the teaching practice of advanced mathematics, it is unclear whether the effect of the application has really played a role in improving the quality of higher mathematics teaching. In addition, the current research on the SPOC model has remained at the theoretical stage. There are few SPOC model studies for specific disciplines, especially higher mathematics curriculum subjects. Therefore, there is a lack of theoretical support in the specific application process, and even some teachers only The simple pursuit of the application form does not focus on the application of actual results. As a result, the SPOC model is in a superficial form and does not play any substantive role.

\section{The Value of Innovative SPOC Mode in Higher Mathematics Courses}

In the practice of basic discipline education, SPOC education in advanced mathematics curriculum is an important content, which is of great significance for improving students' comprehensive quality. Under the traditional education system, the focus of the teaching focuses on the improvement of students' test-taking ability, and little attention is paid to student ability. However, in today's social environment, various ideas have begun to influence students from different perspectives, and new requirements have also been put forward for higher mathematics curriculum education. In education practice, through a variety of ways to innovate the SPOC education model of higher mathematics courses, students can improve the sense of identity and acceptance of teachers, help students to have a clearer understanding of the outside and self, and guide students to better learn and Life [4]. In this regard, as teachers, we must not lose sight of the importance of SPOC education in higher mathematics courses, but we must innovate concepts and methods, constantly explore diversified higher mathematics curriculum education models, and provide students with scientific guidance to make students more active and healthy. The mentality of learning advanced mathematics.

In the traditional classroom teaching of advanced mathematics, teachers carefully explained the knowledge and written books in the lecture hall. The relevant mathematics curriculum knowledge is shown and explained. The students listen carefully in class. This teaching method violates the "based" teaching concept does not help the students to effectively train the innovative thinking of advanced mathematics courses. Therefore, by conducting information-based teaching in the advanced mathematics curriculum classroom, teachers can use multimedia courseware, micro lesson video, and SPOC model information-based teaching methods to guide students to conduct self-study before class in accordance with learning needs and conduct free exchange discussions in class. After reviewing and consolidating after class, it is truly possible to carry out classroom teaching activities based on the students' learning needs. This can ensure that students can apply their knowledge and apply their thinking, and ultimately realize the effective cultivation of innovative thinking in advanced mathematics courses.

\section{Innovation Path of SPOC Education Mode in Higher Mathematics Course}

\subsection{Timely summary of experience in SPOC teaching}

The lack of SPOC teaching experience is one of the key issues affecting its effective application in 
higher mathematics curriculum teaching. Therefore, in order to solve this problem, higher mathematics curriculum teachers should sum up experience in the process of application in order to make better use for the future. The SPOC model provides a certain reference and reference. It can also find problems and solve problems in the process. In the process of applying the SPOC model, complete basic technical support is crucial. The richness of network resources directly affects the application effect of the SPOC model. In the student learning process, students of different basic levels have knowledge of higher mathematics courses. The learning requirements are not the same, so the abundant SPOC mode teaching resources can satisfy the students of different levels of learning to the utmost. Only by continuously providing rich advanced mathematics curriculum learning resources and providing strong basic technical support, can the SPOC model be truly used. Expected effect, to achieve the purpose of teaching students in accordance with their aptitude [5].

\subsection{Continuously Improve the Professional Quality of Higher Mathematics Teachers}

In the process of student learning, the role of the teacher is crucial. Under the current education situation, the existing educational concepts of higher mathematics curriculum teachers can no longer meet the actual needs of the educational development situation, especially in the process of applying the SPOC model. The original teaching philosophy of advanced mathematics teachers cannot meet the requirements. That is to say, to make the SPOC model give full play to the role of improving the teaching quality of higher mathematics courses, it is necessary to update teachers' existing teaching concepts and enhance the professional teaching ability of disciplines. Less critical links. In this regard, schools should organize and strengthen the professional study of teachers of higher mathematics courses, improve teachers' teaching ability, change the teaching thinking of solidified higher mathematics courses, and fully understand the teaching advantages of the SPOC model, so as to better carry out higher mathematics teaching.

\subsection{Use SPOC Mode to Reduce Students' Learning Burden}

The SPOC model has changed the previous teaching model. Under the environment of exam-oriented education, how can we effectively play the role of the SPOC model? It is a problem worthy of in-depth study to improve the quality of higher mathematics teaching while also reducing student learning pressure. In the process of using the SPOC model for advanced mathematics teaching, it is necessary to get rid of the shackles of traditional teaching methods, not to give students excessive learning pressure, to reduce the heavy task of doing tasks, and to allow students to have enough time for course learning and feedback. Experience the joy of success, mobilize the students' enthusiasm for learning, innovate teaching methods, promote the better application of the SPOC model in higher mathematics teaching, and truly realize the intended purpose of improving teaching quality.

\subsection{Pay attention to the fun of SPOC education}

Contemporary students are active in thinking and are more active in learning about the courses they are interested in. Therefore, higher mathematics teachers should use SPOCs to cultivate students' curiosity and curiosity. First of all, teachers should increase the interest of teaching, make the dull and dreary atmosphere of learning become lively and relaxed, thereby reducing the difficulty of classroom teaching and improving teaching effectiveness. Second, in view of the practical difficulty of higher mathematics teaching, teachers should optimize the teaching process, improve the science and rationality of classroom teaching, and make students interested in interesting and interesting topics, so that students can concentrate on higher mathematics classes. , interest in higher mathematics knowledge has improved. Finally, starting from the teaching methods and focusing on cultivating students' interest in learning, we ensure the smooth implementation of interesting teaching and ensure that the classroom teaching achieves positive results.

\subsection{SPOC teaching should be student-centered}


In order to avoid the teacher's rigid teaching mode affecting contemporary students' learning emotions and enthusiasm, higher mathematics teaching should focus on cultivating students' autonomy, and use the SPOC model to stimulate the enthusiasm of students' independent learning. On the one hand, teachers should carefully analyze the student's temperament and learning status, and formulate different teaching plans based on the students' learning foundation, learning ability, and the difference in the level of understanding. Students should be taught at the same time. On the other hand, students occupy the core position in higher mathematics teaching. Under the guidance of teachers, students should independently study, actively answer questions, actively participate in class discussions, and give full play to students' enthusiasm for learning and initiative. It is worth noting that teachers should also cultivate students' ability to think independently, encourage students to think hard, and use them to solve difficulties in higher mathematics learning. The ability to think independently is increasing.

\subsection{Pay attention to SPOC inquiry teaching}

The emphasis of advanced mathematics lies on the ability to train contemporary students in analyzing problems, solving problems, and practicing hands-on skills. Teachers should inspire students' learning pleasure, cultivate students' hands-on abilities, deepen students' understanding of advanced mathematical theory knowledge, and improve the teaching of higher mathematics. overall effect. The use of inquiry-based teaching model in higher mathematics SPOC teaching, namely research-based teaching method, is one of the major measures for teaching model innovation. Teachers should actively create students' sense of inquiry and spirit, inspire students' thirst for knowledge, and enable students to develop their thinking. Find out the learning methods and habits that are most consistent with one's own and give full play to the students' spirit of learning and exploration to improve the teaching effect of higher mathematics. Teachers should encourage students to think independently, and encourage students to express their opinions on higher mathematics knowledge, and effectively cultivate students' thinking ability and language presentation skills, so as to enhance students' comprehensive ability. In the end, teachers should formulate specific inquiry-based teaching programs based on students' learning situations so that they can be used in advanced mathematics classes. Each student can participate in class discussions with the learning method of "independence, inquiry, and cooperation" to enhance contemporary learning. Students' cooperation and communication skills.

\section{Summary}

In summary, in the teaching practice of advanced mathematics, teachers should innovate teaching ideas, change teaching methods, seek SPOC teaching strategies, effectively mobilize the enthusiasm of students, allow students to participate in teaching, and according to the characteristics of teaching, Improve teaching efficiency, fully exercise students' practical ability, and improve the overall level of education.

\section{Acknowledgement}

This research was financially supported by the Education's 2017 Yueqian Technology Cooperative Education Project, (Grant NO. 201702071032).

\section{References}

[1] Wu Peipei, Xu Li, Sun Yuqin. Exploration and Practice of Higher Mathematics Course Based on SPOC, Value Engineering, 2018(2):254-256.

[2] Cheng Pengjun. Application of SPOC in Advanced Mathematics Teaching in Higher Vocational Education, Sanitation Vocational Education, 2017(10):66-67. 
[3] Wu Lan. Research on the application of flipped classroom teaching model based on SPOC in higher vocational education, Computer Knowledge and Technology, 2016(33):151-153.

[4] Wang Zeyan, Yao Jia. The practice and thinking of SPOC mixed teaching mode in advanced mathematics, College Mathematics, 2017(1):91-95.

[5] Luo Xiaoli. Application of SPOC in Higher Mathematics Teaching in Higher Vocational Colleges, Examination Weekly, 2018(25):96. 